Deshpande, N., Wang, D.Y., Bulbrook, R.D. \& McMillan, M. (1965) Hormone studies in cases of testicular feminization. Steroids, 6, 437.

Hauser, G.A., Keller, M., Koller, T., Wenner, R. \& GlooR, F. (1957) Testikuläre "Feminisierung" bei Erwachsenen. Schweiz. med. Wschr. 87, 1573.

JACKSON, I. (1965) The artificial vagina. J. Obstet. Gynaec. Brit. Cwlth, 72, 336.

McMillan, M. (1966) Five cases of testicular feminization including one with a teratoma of the testis. J. Path. Bact. (In press).
MORRIS, J.M. (1953) The syndrome of testicular feminization in male pseudohermaphrodites. Amer. J. Obstet. Gynec. 65, 1192.

Polani, P.E. (1962) in: Chromosomes in Medicine (Ed. by J. L. Hamerton). Little Club Clinic Dev. Med. No. 5. National Spastics Society and Heinemann Medical Books, London.

Taillard, W. \& Prader, A. (1957) Etude génétique du syndrome de féminization testiculaire totale et partielle. J. Génét. hum. 6, 13.

\title{
Unilateral tubal twin pregnancy
}

\author{
SYLVESTER KRZANIAK \\ B.M., B.Chir., M.R.C.O.G. \\ Obstetric and Gynaecological Registrar, \\ Central Middlesex Hospital, London, N.W.10
}

INTRAUTERINE twin gestation occurs as often as one in every eighty pregnancies, but ectopic and heterotopic twins are relatively uncommon. The heterotopic variety may take several forms, e.g:

(a) Coexisting intrauterine and tubal pregnancy (Kazman \& Burnett, 1953 ; Goodman, Elia \& Friedell, 1960).

(b) Coexisting intrauterine and abdominal gestation (Zarou \& Sy, 1952; Nandi, 1953).

(c) Bilateral tubal pregnancy (Evans \& Goyanes, 1952 ; Williams, 1957).

(d) Coexisting ovarian and intrauterine twins (Rannels, 1953 ; Lawson \& Chouler, 1955).

Primary ovarian twin pregnancies were reported (Modavi, 1962; Green \& West, 1963). This is the rarest form of twinning.

Unilateral tubal twin pregnancy is still very rare. In 1955 Unger reported one case and, reviewing the world's literature, stated that by then there were only seventy-nine cases. This figure was confirmed by others (Bucklin \& Myint, 1959 ; Borrow \& Schreiber, 1961 ; Loh \& Loh, 1962).

Bucklin \& Myint (1959), however, reported their case as the eightieth, whilst in Loh's (Loh \& Loh, 1962) estimation this was the eighty-third case reported in the literature. Borrow \& Schreiber (1961), on the other hand, said that their two cases brought the total number of unilateral tubal twins to eighty-one cases.

This disparity can be explained by the fact that Bucklin \& Myint (1959) did not take into account three cases published in 1957 and 1958 (Fill \& Ross, 1957; Fara \& Varga, 1957; Demick \& Cavanagh, 1958). Borrow seemed unaware of the above three publications as well as that of Bucklin in 1959, and Loh \& Loh (1962) made no reference to the two Borrow cases.

If the above corrections are made respectively, the total number of published unilateral tubal pregnancies by 1962 was eighty-six.

\section{Case report}

Mrs T.S., 32 years old, Indian, Gravida III, para I, was admitted into the Casualty Department on 4 September 1964 with a history of increasing lower abdominal pain of 1 day's duration, accompanied by nausea. She also volunteered that she had some pain in the right shoulder. This episode was preceded by lower abdominal pain and discomfort of 3 days' duration, 8 days prior to admission.

Her menstruation started at the age of 15 . The periods were regular occurring every 28 days and lasting 4 days. The last menstrual period occurred on 16 June 1964. Her husband had died of 'sudden heart attack' on 26 June 1964 and she attributed her amenorrhoea to shock but a Primodos pregnancy test on 14 August 1964 was positive.

Her only child was born in 1949 the third stage being complicated by a retained placenta. She also had had two abortions at 10 weeks gestation in 1949 and 1954.

There was no history of serious illnesses or operations.

On examination her general condition was satisfactory. The temperature was $99^{\circ} \mathrm{F}$. Her pulse was regular at the rate of $80 / \mathrm{min}$. Blood pressure was $100 / 60 \mathrm{mmHg}$. There was no evidence of shock. The breasts were active. Cardiovascular and respiratory systems were normal. The lower abdomen was slightly distended, the hypogastrium was tender and there was marked rebound tenderness in both iliac fossae. An ill-defined mobile, tender swelling was palpable in the right iliac fossa.

There was no vaginal bleeding or discharge. The uterus was enlarged and corresponded in size to an 8-week gestation. The cervix was congested, closed and there was marked cervical excitatory pain. Both fornices and the pouch of Douglas were very tender.

There was a cystic mobile swelling $10 \mathrm{~cm}$ in 
diameter (see Fig. 1) in the right adnexum, separate from the uterus and so tender that a more detailed examination of it was impossible.

The haemoglobin level was $80 \%(11.8 \mathrm{~g})$, white blood cell count was $10,600 / \mathrm{mm}^{3}$, and a midstream specimen of urine did not reveal any pathogens. The blood group was B rhesus (D) positive.

A diagnosis of an ectopic gestation with slow intraperitoneal bleeding was made, but because of the size of the swelling, a possibility of an ovarian cyst complicating pregnancy and undergoing some pathological changes (bleeding or torsion) was contemplated.

Laparotomy was performed and the examination of the pelvic content showed:

The ampulla and the fimbriated end of the right Fallopian tube were thickened and distended to a diameter of $10 \mathrm{cur}$. The ffmbriated end of the tube was dilated to about $1.5 \mathrm{~cm}$ and the foetal membranes could be seen through it. The placental tissue penetrated the muscular layer of the gravid tube at several points, which were oozing blood. The left tube was kinked and bound to the posterior wall of the uterus by adhesions. There were also adhesions between the large gut, tubes and ovaries, all suggesting previous pelvic inflammation. Both ovaries were normal, corpus luteum being in the right ovary. The uterus was enlarged and corresponded in size to 8 weeks of gestation. The pouch of Douglas contained some fresh blood and an old blood clot. The total blood loss was estimated as $10 \mathrm{oz}(220 \mathrm{ml})$.

Right salpingectomy was performed. Macroscopic examination of the removed tube revealed a twin pregnancy corresponding to about 12 weeks of gestation (Fig. 1).

The post-operative period was uneventful and the patient was discharged from the hospital on 18 September 1964, her haemoglobin being $77 \%$ $(11.0 \mathrm{~g})$. The subsequent follow-up in the Outpatient's Department was satisfactory.

\section{Comments}

This case supports the generally accepted view that the commonest aetiological factor in ectopic gestation is infection. In this instance manual removal of placenta and two incomplete abortions provided ample opportunity for the pathogens to enter and damage the Fallopian tubes.

This ectopic is unusual, not only because of the twins, but also because of the large size to which the gravid tube was distended without rupture.

The incidence of unilateral twin tubal pregnancy is difficult to estimate, but one can reasonably assume that this occurs more often than the literature would imply. In the first instance not all cases are reported, and the reviews of the literature

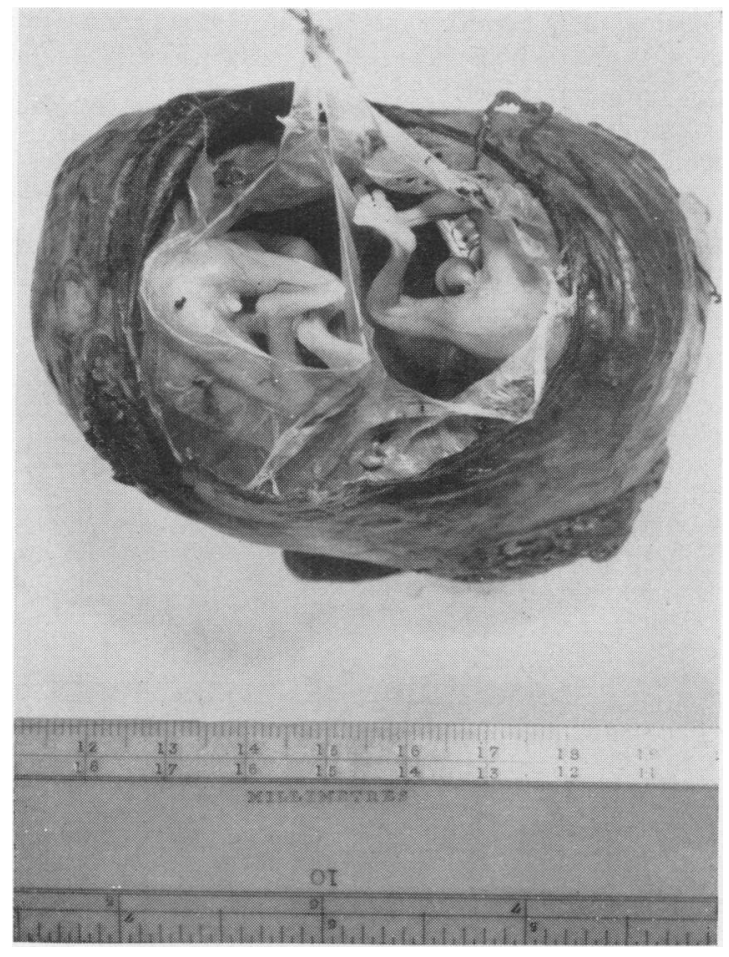

Fig. 1. Gravid fallopian tube opened to show twins in situ.

are often incomplete. Secondly, twins can be lost in the abdominal cavity particularly in the early stages when often the embryo is not found at laparotomy despite definite evidence of a ruptured ectopic gestation. Thirdly, among tubal abortions that resolve spontaneously some may be twin abortions.

\section{Summary}

A case of unilateral twin tubal pregnancy is described. An attempt was also made to explain the disparity of opinion of different authors regarding the incidence of this type of ectopic. Reasons for possible more frequent incidence of unilateral twin tubal gestation than stated in the literature are suggested. Other types of heterotopic and ectopic twins are listed.

\section{Acknowledgments}

I would like to thank Mr J. S. MacVine for his permission to publish this case and $\mathrm{Mr}$ A. Booker for taking the photograph.

\section{References}

BORROW, M.L. \& SCHREIBER, I. (1961) Unilateral twin tubal pregnancy. Amer. J. Obstet. Gynec. 81, 1230.

BUCKLIN, R. \& MYINT, M.K. (1959) Unilateral tubal twin pregnancy. Amer. J. Obstet. Gynec. 77, 1307. 
Demick, P.E. \& Cavanagh, D. (1958) Unilateral tubal twin pregnancy. Amer. J. Obstet. Gynec. 76, 533.

Evans, G.E. \& Goyanes, E. (1952) Bilateral ectopic gestation. Amer. J. Obstet. Gynec. 64, 444.

FARA, F.J. \& VARGA, A. (1957) Interstitial twin pregnancy with cornual rupture. Obstet. and Gynec. 10, 579.

FILL, L. \& Ross, C.V. (1957) Unilateral tubal twin pregnancy. Obstet. and Gynec. 9, 358.

Goodman, D., Elia, A.D. \& Friedell, G.H. (1960) Simultaneously aborted intrauterine and tubal pregnancies. Obstet. and Gynec. 16, 53.

GREEN, G.H. \& WEST, S.R. (1963) Ovarian twin pregnancy. Obstet. and Gynec. 21, 126.

Kazman, H.A. \& BARNeTT, L.A. (1953) Simultaneous ruptured ectopic and intrauterine pregnancy. Surgery, 33, 391.

LAWSON, J.G. \& CHOuler, J.G. (1955) A case of primary ovarian pregnancy with coexisting intrauterine gestation. J. Obstet. Gynaec. Brit. Emp. 62, 951.

LOH, W.P. \& LOH, H.Y. (1962) Unilateral tubal twin pregnancy with intraperitoneal rupture. Obstet. and Gynec. 19, 267.

Modavi, O. (1962) Primary twin ovarian pregnancy with ovarian endometriosis. J. Obstet. Gynaec. Brit. Cwlth, 69, 655.

NANDI, G. (1953) Combined full-time intrauterine and extrauterine pregnancy with survival of mother and both children. J. Obstet. Gynaec. Brit. Emp. 60, 114.

RANNELS, H.W. (1953) Simultaneous intrauterine and extrauterine (ovarian) pregnancy. Obstet. and Gynec. 2, 281.

UNGER, H.M. (1955) Intratubal twin pregnancy with rupture. Amer. J. Obstet. Gynec. 69, 1362.

Williams, P.C. (1957) Bilateral tubal pregnancy. Amer. J. Obstet. Gynec. 74, 1132.

ZAROU, G.S. \& SY, A. (1952) Combined intrauterine and extrauterine pregnancy progressing to term. Amer. J. Obstet. Gynec. 64, 1338.

\title{
Simultaneous myasthenia gravis and pernicious anaemia:
}

\author{
A case report with organ antibody studies \\ T. E. BLECHER \\ M.B., B.Ch., M.R.C.P.(Ed.), M.C.Path. \\ Senior Registrar in Pathology (Haematology) \\ E. R. Williams \\ M.B., B.Chir., M.A., M.R.C.P. \\ Locum Senior Registrar in Medicine
}

The Royal Infirmary, Bristol 2

Myasthenia GRAVIS and pernicious anaemia are both conditions in which organ-specific autoantibodies are being reported with increasing frequency. Their coexistence in a single patient provides some support for the belief that they have a common pathogenesis, namely a breakdown in the immunological self-recognition mechanisms leading to autoimmune disease.

This combination occurred in eleven of 857 cases of myasthenia gravis seen at the Mayo Clinic prior to 1960 and reviewed by Howard, Silverstein \& Mulder (1965) but no antibody studies were performed in that series. Nine cases of macrocytic anaemia were noted in Simpson's series of 491 myasthenic patients (Simpson, 1960, 1964). Simpson (1966) states that some, if not all, of these patients were later shown certainly to have pernicious anaemia. Only one, however, was available for immunological studies and in that patient the further complication of Hashimoto's disease was found at necropsy; gastric and thyroid antibodies were demonstrated. The only other report of the coexistence of pernicious anaemia and myasthenia gravis alone which we have been able to trace is that of Rowland $e t$ al. (1956). This was, of course, prior to the era of organ-specific antibody studies in these diseases.

The present report is of a further instance of this association, and in this case the two diseases presented simultaneously. Immunofluorescence studies showed the presence in the patient's serum of organ specific antibodies to the 'target tissues' of both of these diseases, namely skeletal muscle and gastric mucosa. We have also reviewed the case histories of all the myasthenic patients seen at this hospital since 1953 and some of those seen at the attached Bristol Eye Hospital. There were no further instances of pernicious anaemia in a total of thirty-seven cases, but several patients did have other diseases, possibly autoimmune, which we mention below.

\section{Case report}

A 62-year-old French polisher developed double vision and drooping of the left eyelid within the course of a week in March 1965 . He was seen by one of us on 10 June, when he also admitted to dropping of the jaw on talking, difficulty in chewing and exhaustion after the slightest exertion. Symptoms were absent on waking, were improved by rest and were made noticeably worse by sunlight. He had lost $20 \mathrm{lb}$ in weight in the 